LICENÇA CC BY:

Artigo distribuído sob os termos

Creative Commons, permite uso e distribuição irrestrita em qualquer meio desde que o autor credite a fonte original.

\section{O GESTO É A ESCRITA NO AR: REPRESENTAÇÃO IDEATIVA DE PALAVRA E APROPRIAÇÃO DA ESCRITA EM VIGOTSKI}

THE GESTURE IS WRITING IN THE AIR: IDEATIONAL REPRESENTATION OF THE WORD AND APPROPRIATION OF WRITING IN VYGOTSKY LA SEÑAL ES LA ESCRITA EN EL AIRE: REPRESENTACIÓN DE IDEA DE PALABRA Y APROPIACIÓN DE LA ESCRITURA EN VYGOTSKY

Adriana Fatima Franco ${ }^{1}$

Lígia Márcia Martins²

'Programa de Pós-Graduação em Psicologia, Universidade Estadual de Maringá, Maringá, PR, Brasil.

2Programa de Pós-Graduação em Educação Escolar, Universidade Estadual Paulista "Júlio de Mesquita Filho", Araraquara, SP, Brasil.

Artigo recebido em: 10/10/2019

Aprovado em: 14/10/2020

Resumo: Este texto de natureza teórica focaliza o desenvolvimento da linguagem escrita como função psíquica superior. Seu objetivo é apontar a representação ideativa da palavra como unidade mínima de análise para a compreensão do desenvolvimento da linguagem escrita. Ao afirmar que escrever é grafar ideias, esta análise ampara-se na perspectiva histórico-cultural de desenvolvimento humano. Ao longo da presente exposição e tomando como eixo a periodização da formação de conceitos em Vigotski, buscamos analisar a apropriação da escrita a partir do conceito de palavra. Apontamos que o ato psíquico consubstanciado na escrita não radica no trato ou no uso externo que a criança faz da palavra oralmente, mas sim de sua representação como conceito. Advogamos, pois, que a formação do conceito de palavra, tanto em sua dimensão semântica, quanto em sua morfologia e fonética, se impõe como tarefas de um ensino desenvolvente desde a educação infantil, construindo-se, assim, o substrato para a aquisição da escrita propriamente dita nos anos de escolarização subsequentes.

Palavras-chave: Desenvolvimento da escrita; Psicologia Histórico-Cultural; Conceito de palavra.

Abstract: This theoretical text focuses on the development of written language as a higher mental function. It aims to highlight the ideational representation of the word as a minimum unit of analysis for understanding the development of written 
language. By affirming that writing is to write ideas, this analysis is supported by the historicalcultural perspective of human development. Throughout this essay, and taking as its axis the periodization of the formation of concepts in Vygotsky, we analyze the appropriation of writing from the concept of word. We point out that the psychic act embodied in writing is not based on the treatment or on the external use that the child makes of the word orally, but in its representation as a concept. We argue, therefore, that the formation of the concept of word, both in its semantic dimension and in its morphology and phonetics, is imposed as tasks of a developmental education from early childhood education, thus building the substrate for the appropriation of writing itself, in the subsequent school years.

Keywords: Writing development; Historic-cultural psychology; Concept of word.

Resumen: En este texto de naturaleza teórica se focaliza el desarrollo del lenguaje escrito como función psíquica superior. Su objetivo es apuntar la representación de idea de la palabra como unidad mínima de análisis a la comprensión del desarrollo del lenguaje escrito. Al afirmar que escribir es grafiar ideas, este análisis se ancla en la perspectiva histórico-cultural de desarrollo humano. A lo largo de la presente exposición y tomándose como eje la periodización de la formación de conceptos en Vygotsky, se busco analizar La apropiación de la escritura a partir del concepto de palabra. Apuntamos que el acto psíquico consubstanciado en la escritura no radica en el trato o uso externo que el niño hace de la palabra oralmente, pero sí, de su representación como concepto. Abogamos, pues, que la formación del concepto de palabra, en su dimensión semántica y en su morfología y fonética se imponen como tareas de una enseñanza desarrollada desde la educación infantil, construyéndose, así, el substrato a la adquisición de la escritura propiamente dicha, en los años de escolarización subsecuentes.

Palabras clave: Desarrollo de la escrita; Psicología histórico-cultural; Concepto de palabra.

\section{Introdução}

O enfoque histórico-cultural acerca da apropriação da escrita implica situá-la, de partida, como função psíquica superior, haja vista que seu domínio promove um processo de complexificação do psiquismo humano. Compreendê-la passa, obrigatoriamente, por buscar sua gênese na história do desenvolvimento psíquico. Destacamos que a criança não nasce com as funções psíquicas complexas ou tipicamente humanas desenvolvidas, serão necessárias atividades que requeiram tal desenvolvimento, como defende Leontiev (1978). Para aclarar esse processo de humanização, Vigotski nos apresenta a lei geral do desenvolvimento ao assinalar que os processos funcionais, em princípio, despontam no plano social, como categoria interpsíquica, e serão internalizados, transformando-se em ferramentas psíquicas. Sendo assim, tornar-se 'intra' significa tornar-se ferramenta do psiquismo, e essa conquista demanda tempo, necessita de mediações cada vez mais acuradas, pois se vincula diretamente à situação social de desenvolvimento da criança.

Partimos da assertiva de que não é a mão que escreve, e sim o pensamento. Escrever é grafar ideias e para tanto será necessário que a criança seja capaz de abstrair o aspecto sensorial da fala e avançar na construção de uma linguagem que não usa a palavra oral, e sim sua representação. Essa atividade arbitrária, voluntária, exige um autocontrole do comportamento 
mais elevado do que as atividades desenvolvidas anteriormente à aquisição da fala. Para escrever serão precisos o domínio de signos e a apropriação do conceito de palavra, dados que nos exigem aclarar o que esta seja.

De forma sucinta, apontamos que toda palavra é composta por uma face fonética e uma face semântica. Martins (2013), com base em Vigotski e Luria, explica que estes autores propõem uma distinção entre as faces fonética e semântica da palavra. Para ambos, a face fonética compreende a representação do objeto sensível, a possibilidade de conversão do objeto em expressão sonora representada em sua denominação. A face semântica inclui essa face e a supera, visando à representação simbólica do objeto, à representação da essencialidade que sua manifestação fenomênica oculta; sinalizam os autores que essas faces não se identificam nem se desenvolvem linear e paralelamente.

Isto posto, comecemos por analisar mais especificamente o significado da palavra e seu papel fundante na construção do psiquismo. O significado da palavra ocupa um lugar de destaque na obra de Vigotski. Martins (2013, p.67, grifo nosso) ressalta que o autor "[...] identifica na palavra o signo dos signos, isto é, a unidade de análise nuclear no estudo do comportamento complexo". Se no primeiro ano de existência operamos e estruturamos nossa consciência por meio da sensação e da percepção, centralmente pela unidade percepçãoemoção-ação, a linguagem simbólica trará transformações radicais na vida da criança e as conexões primárias entre pensamento e linguagem ultrapassarão a conexão direta objeto/ designação, e possibilitarão que a criança se despregue do aqui e agora e duplique o mundo externo internamente.

Ao estudar o processo de significação pelo 'método de análise por unidade', Vigotski (1995) nos indica que a palavra é a unidade do pensamento e da linguagem. Isso porque, segundo o autor, a palavra aponta a pré-história tanto da linguagem quanto do pensamento, e revela-se fundante das relações internas desses processos. Nas palavras do autor,

Encontramos no significado da palavra essa unidade que reflete de forma mais simples a unidade do pensamento e da linguagem. O significado da palavra [...] é a unidade indecomponível de ambos os processos e não podemos dizer que ele seja um fenômeno da linguagem ou do pensamento. A palavra desprovida de significado é um som vazio. Logo, o significado é um traço constitutivo indispensável da palavra. É a própria palavra vista no seu aspecto interior. Deste modo, parece que temos todo fundamento para considerá-la como um fenômeno de discurso. Mas, como nos convencemos reiteradas vezes, ao longo de toda nossa investigação, do ponto de vista psicológico o significado da palavra não é senão uma generalização ou conceito. Generalização e significado da palavra são sinônimos. Toda generalização, toda formação de conceitos é o ato mais específico, mais autêntico e mais indiscutível de pensamento. Consequentemente, estamos autorizados a considerar o significado da palavra como fenômeno do pensamento. (VIGOTSKI, 1995, p. 398, grifo nosso).

Com esses pressupostos, depreendemos a representação ideativa de palavra como unidade mínima de análise para a decodificação da gênese e desenvolvimento da linguagem 
escrita, uma vez que sem a referida representação a palavra não se objetiva como conceito, e na ausência deste, as conexões internas entre linguagem e pensamento resultam artificiais. O ponto central de nossa análise é a compreensão do processo de desenvolvimento da representação ideativa da palavra. Buscamos apresentar a palavra como ideia (conceito) enquanto unidade mínima para a compreensão da apropriação da língua escrita, pois esta concentra as múltiplas relações envolvidas na apropriação da escrita, recolocando em si o papel do ensino e da aprendizagem. Consideramos que a ideação de palavra aponta o caminho para a compreensão da escrita, porque sintetiza a base material/ideal de sua elaboração. Conforme Vigotski (2001, p. 313, grifo nosso),

Até essa idade [escolar], através de uma linguagem de sons, a criança já atingiu um estágio bastante elevado de abstração em relação ao mundo material. Agora ela tem pela frente uma nova tarefa: deve abstrair $o$ aspecto sensorial da sua própria fala, passar a uma linguagem abstrata, que não usa palavras mas representações de palavras.

Ressaltamos que a escrita não reproduz o caminho da linguagem falada, entretanto será por meio da apropriação da palavra - na condição de conceito -que surgirá a possibilidade de representação e, portanto, do desenvolvimento da 'ideia de algo'. Voltemos aos primórdios da escrita. Esta se inicia muito antes de a criança fazer uso do lápis como ferramenta. Vigotski (1995) nos aclara que a escrita se inicia quando aparecem os primeiros signos visuais e se sustenta na mesma história natural do nascimento dos signos. Segundo o autor, "[...] o gesto, precisamente, é o primeiro signo visual, que contém a futura escrita da criança como a semente contém o futuro carvalho. O gesto é a escrita no ar e a escrita é, frequentemente, um gesto que se fixou"(VIGOTSKI, 1995, p. 128).

Corroborando Vigotski (1995), o domínio da linguagem escrita é o resultado de um longo processo de desenvolvimento das funções superiores. Em sua acepção, apenas se abordarmos a escrita de um ponto de vista histórico, com a intenção de compreendê-la ao longo de todo o desenvolvimento histórico-cultural da criança, poderemos avançar para além das compreensões que se limitam a trazê-la como ato motor específico e que circunscrevem o ensino ao traçado de letras e à escrita de palavras. Complementa ser "[...] preciso ensinar à criança a linguagem escrita e não a escrita das letras" (VIGOTSKI, 1995, p. 203).

Ainda no caminho da compreensão da escrita, Martins (2013) explana que o domínio da linguagem escrita representa o domínio de um sistema simbólico altamente complexo. Em consonância com a autora, a escrita se edifica sobre a base pelos processos de percepção, atenção, memória, linguagem oral, pensamento e sentimento. Dessa forma, aprender a ler passa necessariamente pela aprendizagem do domínio dos signos. Nessa direção, Vigotski (1995, p.185, grifo nosso) expõe que "[...] para que a linguagem escrita da humanidade se converta em linguagem escrita da criança, são necessários complexos processos de desenvolvimento".

Sendo assim, pensamos que compreender a escrita perpassa, necessariamente, por compreender o psiquismo, mais precisamente a trajetória do desenvolvimento da linguagem oral ao longo dos primeiros anos de desenvolvimento da criança em sua atividade. Quando a criança faz uso da palavra/conceito, tem-se a possibilidade da representação de algo, e 
esse momento marca o início de um longo processo que traz em seu bojo a possibilidade do desenvolvimento da escrita como ferramenta psíquica. O ponto de partida para a compreensão desse processo é a palavra - a palavra é o signo dos signos -, mas será preciso explicitar como a palavra se edifica na qualidade de conceito, como ocorrem as relações internas entre ideias que se expressam no significado da palavra. Essa afirmativa nos leva a retomar a construção do conceito de palavra ao longo da ontogênese e suas relações com o processo de apropriação da escrita.

\section{A periodização da formação de conceitos: etapa pré- linguística e período pré-verbal}

Ao considerar que o psiquismo é a unidade material ideal, apoiamo-nos em Leontiev (1978) quando propõe a categoria atividade para a compreensão desse psiquismo. De acordo com este autor, "[...] pela sua atividade, os homens não fazem senão adaptar-se à natureza. Eles modificam-na em função do desenvolvimento das suas necessidades" (LEONTIEV, 1978, p. 265). A criança inicia sua vida em um mundo cultural criado pelas gerações precedentes. Ninguém nasce com imagem mental, para sua construção a criança precisará captar o objeto, o qual deve estar em seu campo perceptual, ainda, para formar a imagem, é necessário afeto. Sendo assim, cada ato sensorial é um ato afetivo (MARTINS, 2013).

Pensar significa ter em seu campo perceptual estímulos que possibilitem a formação de imagens (gestos, músicas, objetos culturais). Se o pensamento está circunscrito ao campo sensório-perceptual, por outro lado a linguagem também está firmada em sua base natural, ou seja, o bebê tem como ferramenta a comunicação: reações vocais reflexo-incondicionadas. Esses são os instrumentos de contato social do bebê nesse período (primeiros meses de vida), essencialmente mecanismos fisiológicos que revelam estados emocionais do organismo. Trata-se de uma etapa na qual a linguagem é pré-intelectual e o pensamento se revela prélinguístico. Ao longo dos primeiros meses de vida, a criança iniciará o processo de 'tomar uma coisa por outra', como, por exemplo, quando a criança chora para chamar a mãe, ela iniciou esse processo. A atividade de comunicação emocional direta não só será engendrada na relação com o adulto, mas será nessa relação que ela ganhará novos contornos.

Ao longo do primeiro ano, novas maneiras de conduta surgem e a motricidade do tipo afetiva paulatinamente é substituída pela que se aproxima da sensório-motora. Como sinal de avanços promovidos no interior da atividade de comunicação emocional direta, Vigotski (1996, p. 287) indica para uma mudança no comportamento do bebê por volta do quintosexto mês de vida,

[...] os primeiros movimentos precisos defensivos, uma preensão mais firme, os primeiros rompantes de alegria, gritos causados por algum movimento desafortunado, talvez os primeiros desejos, tentativas experimentais, reações sociais ao ver crianças de sua mesma idade, busca de brinquedos perdidos. 
Esses modos de comportamento não surgem espontaneamente e estão relacionados à forma como o adulto apresenta objetos, palavras e afetos à criança.

Os adultos que estão no trato com a criança criam possibilidades para que a atividade objetal surja e se complexifique. Chamamos atenção para o papel da imitação nesse período; o bebê vê a realidade e a si mesmo pelo adulto e busca imitar suas expressões faciais e seus gestos. Acerca da relação criança-adulto, consideramos que a premissa de Mendonça (2017) sobre a necessidade de estimulação auditiva situa a centralidade dessa relação. Segundo o autor, a criança precisa ser estimulada auditivamente para que as conexões sensoriais ativem as áreas de projeção primária; se a fala do outro não fizer a estimulação, a criança não formará a habilidade de constituir os sons da língua materna.

Dessa sentença destacamos o fato de que a constituição do humano na criança só será possível se houver um outro que a alce a esse patamar. As funções ditas naturais, regidas por mecanismos biológicos, serão transformadas sob a ação da cultura. Nesse momento, temos uma independência entre linguagem e pensamento. A imagem do objeto está sendo construída e com ela o pareamento com o som. Nesse período, denominado período pré-verbal, há um desenvolvimento do balbucio, gesto e gesto indicador. Entretanto, para que essas conquistas ocorram, não se trata de ficar falando com o bebê, mas de falar e apresentar o objeto, realizar o pareamento (linguagem-som-objeto). Acerca dessa questão, Martins (2013), fundamentada nos pressupostos de Luria e Vigotski, sinaliza que nesse momento a criança assimila apenas que cada objeto corresponde a uma palavra que o denomina e, ainda, a palavra que identifica o objeto se revela como mais uma de suas propriedades, como extensão do próprio objeto.

A necessidade de falar surge para controlar o comportamento do outro e satisfazer seus desejos. É desse movimento que surgirá a atividade guia do próximo período: objetal manipulatória. Conforme Vigotski (1996), a primeira utilização de ferramentas e o emprego de palavras se dão para expressar o seu desejo e marcam o final desse período, originando uma etapa completamente nova para a criança. O final do primeiro ano será marcado por três elementos, cuja transitoriedade dos conteúdos sinaliza o fim do período estável: o andar (quase anda), as expressões relativas aos afetos e às vontades da criança (birra) e o desenvolvimento da linguagem (quase fala). Com esses elementos, a criança estabelece uma relação com o outro e, nos dizeres de Vigotski (1996, p. 329), "[...] partindo da imitação, gesticulação e fonação fazem com que a criança aproprie-se das palavras em seus aspectos fônicos e semânticos. Na dificuldade de entendimento reciproco surge um processo de mediação entre os aspectos da linguagem".

Martins (2013) expressa que a criança pronuncia as primeiras palavras, mas a conexão entre estas e o objeto é externa e não interna, isto é, não é representativa de conexões entre signos e significado. A fala da criança é a palavra na condição de equivalente funcional da mesma que, a rigor, ainda não o é. Isso porque a palavra pressupõe, necessariamente, o seu entrelaçamento com o pensamento. A criança viverá aqui seu primeiro desafio: entender que a linguagem versa sobre categorias e não acerca de objetos isolados. 
Esse momento de transição é caracterizado pela presença da linguagem autônoma e possui peculiaridades nos aspectos motor, articulatório e fônico. Os significados das palavras são diferentes dos significados apresentados pelos adultos, a criança será capaz de compreender antes de conseguir se expressar por meio de palavras e os significados das palavras serão elaborados ativamente por ela.

Ao discorrer acerca do papel da linguagem autônoma, Vigotski (1996) enfatiza que, sem a formação desse tipo de linguagem, a criança jamais haveria passado do período de desenvolvimento pré-linguístico ao verbal. Em síntese, a criança descobriu a existência do objeto, consegue pegar, manipular, jogar e terá como desafio buscar compreender seu uso social. O uso que ela faz de um lápis é o mesmo dado a outros objetos: pega, manipula, coloca na boca e joga no chão. Ao tratar dessa questão, Mendonça (2017, p.63) exemplifica com o uso do giz, pontuando que"[...] o adulto, ao apresentar o objeto à criança, o faz utilizandose das formas de uso, acompanhadas pelo significado da palavra e do gesto, transmitindo culturalmente a ideia de uso do pedaço de giz".

Já dissemos que o que caracteriza a situação social de desenvolvimento da criança, ao longo do segundo ano de vida, é a dependência da situação concreto-visual. O processo de pensamento no início desse período tem como centro o campo perceptual concreto: "[...] pensar significa orientar-se nas relações afetivas dadas e atuar de acordo com a situação externa que percebe. Na idade mencionada, impera a percepção visual-direta, afetivamente matizada, que se transforma de imediato em ação" (VIGOTSKI, 1996, p. 345).

Sendo assim, a criança nessa idade possui uma atividade intelectual, porém pensar ainda não significa lembrar, isto porque a consciência está estruturada por meio da percepção; outras funções, como a memória e a atenção, se realizam por meio dela. Desse modo, o ensino precisa ajudar a criança a engendrar uma nova forma de atividade. Trabalhar a escrita nesse momento demanda possibilitar que a criança dê início ao processo de representação da realidade, ensinando-a a captar o conceito de palavra. Por exemplo, ao ensinar a palavra 'copo', será necessário apresentar vários copos de cores, tamanhos e formas diferentes, pois assim a criança poderá abstrair a ideia de copo e compreender que a palavra 'copo' representa uma classe de objetos e não apenas um 'copo' em particular. A compreensão do conceito do que seja palavra é central para o ensino da escrita.

\section{O entrecruzamento linguagem e pensamento: o nascimento da possibilidade de superar os limites da experiência sensorial}

A utilização de ferramentas sígnicas inaugura uma etapa completamente nova para a criança. A necessidade de controle do comportamento do outro e a busca pela compreensão da função social dos objetos de seu entorno resultam em maior importância nesse período: o desenvolvimento da linguagem em seu entrecruzamento com o pensamento. A criança aprende 
a função social do signo e surge então a possibilidade de representação ideativa do objeto, abstração e generalização. Tem início um longo processo de internalização da linguagem, que perpassa pelo desenvolvimento da linguagem egocêntrica e culmina na linguagem interna, que a rigor é esteira para a futura aquisição da escrita.

Tomemos, para compreensão desse complexo processo, a relação da criança com os objetos. A criança, no início do período da primeira infância, apresentará um maior interesse pelos objetos, manipulará e buscará compreender sua função social. Ela não quer apenas saber o nome dos objetos, mas sua função social, e as conquistas do período anterior: ela já caminha, explora melhor o entorno físico e social, sua percepção está mais acurada, a atenção focal se expressa como guia das ações que realiza, possui um acervo vocabular mais rico que o anterior, etc., o que lhe permite um salto qualitativo no desenvolvimento. Quando ela pergunta: o que é esse?, para além de saber 'como isso se chama'?, ela quer saber 'O que isso faz? Como usa'?. Os gestos do adulto e outras formas 'mudas' de ensino não satisfazem a sua necessidade de compreender a função do objeto, ela passa a requerer essas informações do adulto por meio da linguagem.

Retomamos o exemplo do uso do lápis: quando a criança segura o lápis e com o gesto da mão faz um movimento indicando a ação do desenho, ela está no processo de apropriação do uso desse instrumento. Temos uma criança que reconhece a função social do objeto e é capaz de tomá-lo como ferramenta. Frisamos que a ideia de uso de ferramentas psíquicas é essencial para o surgimento dos rudimentos da escrita. Todavia, a criança poderá se apropriar do uso desse instrumento somente se houver atividades que gerem a necessidade de fazê-lo. $A$ necessidade é central para que o desenvolvimento ocorra e no início da vida essa necessidade é partilhada - adulto-criança. Vigotski (2004, p. 98) pondera que "[...] todo instrumento é necessariamente um estímulo: se não o fosse, ou seja, se não gozasse da faculdade de influir no comportamento, não poderia ser um instrumento. Mas nem todo estímulo é instrumento". Esse destaque acerca de quais estímulos são de fato instrumentos e necessitam da atenção da criança precisa ser realizado pelo adulto.

Por conseguinte, a atividade objetal manipulatória engendra uma nova qualidade psíquica: o desenvolvimento da linguagem e seu entrecruzamento com o pensamento. A apropriação da linguagem duplicará o mundo perceptível, e possibilitará à criança operar com os objetos em sua ausência, ou seja, para além das coisas diretamente observáveis e manipuláveis. A possibilidade de superar os limites da experiência sensorial amplia drasticamente o mundo da criança. É importante reafirmar que, na concepção de Vigotski (1996, p. 396), "[...] o pensamento e a palavra não estão ligados entre si por um vínculo primário. Este surge, modifica-se e amplia-se no processo do próprio desenvolvimento do pensamento e da palavra". São essas conexões primárias entre pensamento e linguagem que ultrapassam a conexão direta objeto/ designação e possibilitam o início do desenvolvimento de conceitos.

A relação entre o pensamento e a palavra é compreendida por Vigotski (2001, p. 409) como "[...] um movimento do pensamento à palavra e da palavra ao pensamento". Martins 
(2013) assevera que, para Vigotski, a palavra é um fenômeno verbal e intelectual na medida em que condensa em si as demandas funcionais tanto da linguagem quanto do pensamento. Essa relação é vista como um processo em desenvolvimento, "[...] o pensamento não se exprime na palavra mas nela se realiza" (VIGOTSKI, 2001,p. 409). Para realizar a análise, o autor distingue dois planos na própria linguagem: o semântico (interno) e o físico sonoro (externo) e pondera que é uma unidade complexa e heterogênea.

Em contrapartida, o desenvolvimento semântico se inicia pelo todo, "[...] o aspecto semântico transcorre em seu desenvolvimento do todo para a parte, da oração para a palavra, ao passo que o aspecto externo transcorre da parte para o todo, da palavra para a oração" (VIGOTSKI, 2001, p. 411). É nesse sentido que Vigotski (2001, p. 412) assinala: "[...] a linguagem não serve como expressão de um pensamento pronto. Ao transformar-se em linguagem, o pensamento se reestrutura e se modifica". Nesse âmbito, compreende que os processos de desenvolvimento dos aspectos semântico e sonoro da linguagem, de sentidos opostos, constituem uma unidade, lembrando que no início da vida a preponderância será do aspecto físico, fonético e teremos a tarefa de auxiliar a criança na construção dos significados, instituintes dos conteúdos do pensamento.

$\mathrm{O}$ ato de falar requer a transição da palavra do plano interior para o plano exterior, enquanto a compreensão pressupõe o movimento inverso, do plano externo da linguagem para o plano interno (VIGOTSKI, 2001). Aqui, temos a apresentação de um conceito central para a compreensão dessa relação: a linguagem interior. Vigotski apresenta a linguagem interior e defende a tese de que se trata de uma formação particular de natureza psicológica, uma modalidade específica de linguagem dotada de particularidades absolutamente específicas e para sua compreensão será necessário o entendimento das relações entre linguagem interior e linguagem egocêntrica.

Vigotski (2001) tomou como hipótese norteadora a ideia de que a linguagem egocêntrica faz parte de uma série de estágios que antecedem a linguagem interior. Com base no estudo genético, chegou a uma lei geral da linguagem egocêntrica: a tendência para abreviação e omissão de palavras, frases, orações. Nesse sentido, a sintaxe se estrutura enfatizando o predicado e ocultando o sujeito, bem como as palavras a ele relacionadas, dando luz ao que Vigotski chama de predicatividade ou tendência à predicatividade absoluta. Tal tendência é particularidade necessária da sintaxe da linguagem interior (VIGOTSKI, 2001). Para o autor, a linguagem egocêntrica contém desde seu surgimento o gérmen social e não é ainda uma fala subjetiva, nesta direção afirma que "[...] a linguagem egocêntrica da criança é uma forma específica de linguagem que já se distingue em termos funcionais e estruturais e, não obstante, por sua manifestação ainda não se destacou definitivamente da linguagem social em cujo seio esteve sempre se desenvolvendo e amadurecendo" (VIGOTSKI, 2001, p. 443). E acrescenta "[...] assim, nos aspectos subjetivos e objetivos essa linguagem é uma forma mista e transitória entre a linguagem para os outros e a linguagem para si - nisto reside a lei básica do desenvolvimento da linguagem interior" (VIGOTSKI, 2001, p. 444). 
Martins (2013, p.180) retoma os estudos de Vigotski e Luria (2007) relativos à fala egocêntrica e explica que estes autores "[...] reiteram o uso da fala egocêntrica como emprego de signo auxiliar ao constatarem, em seus experimentos, que diante de situações complexas o coeficiente desse uso praticamente duplica". Na visão dos autores,

\begin{abstract}
A maior mudança produzida no desenvolvimento da criança se dá quando essa fala socializada, anteriormente dirigida ao adulto, se volta para si mesma, quando, em lugar de apelar ao experimentador com um plano para resolver o problema, a criança apela a si mesma. Nesse segundo caso, a fala que intervém na solução passa desde a categoria de função interpsíquica à de função intrapsíquica. (VIGOTSKI; LURIA, 2007, p. 32).
\end{abstract}

Salientamos que o percurso que culmina na fala interior é longo, e no desenvolvimento das relações entre linguagem e pensamento, a representação é a condição primária para a formação de conceitos. A formação embrionária de conceitos pode ser tomada como equivalente funcional do conceito; pode ter a aparência de conceito, serve à comunicação entre criança e adulto, porém a criança possui o domínio do aspecto externo, sonoro da palavra em relação ao objeto, mas terá um longo caminho até a conquista e o domínio de seu aspecto interno, intelectual. Nessa direção, a formação de conceitos atravessa todos os períodos do desenvolvimento, evidenciando, mais uma vez, o papel da educação escolar junto aos bebês, às crianças, aos jovens e aos adultos (MARTINS, 2013; PORTO, MARTINS 2018).

Vigotski (1996) sustenta que as neoformações da primeira infância estão relacionadas à linguagem e a tomada de consciência só é possível por meio da aquisição da linguagem. É como resultado da aliança entre linguagem e pensamento que os objetos adquirem significados. $O$ que está em questão é ensinarmos a criança a abstrair os traços essenciais dos objetos. Por exemplo, ela terá que aprender que o copo não se identifica à sua materialidade captada pela percepção, mas que possui traços comuns a uma classe. Tomando especificamente a escrita antes de saber o traçado das letras e suas formas, a criança precisa compreender o que é forma.

No cerce dessa questão está o desenvolvimento de conceitos, e ao analisá-los, Vigotski (2001) argumenta que o significado da palavra 'evolui' e, ao longo da vida, teremos diferentes formas qualitativas de generalização. Para tanto, o autor apresenta três grandes períodos referentes ao desenvolvimento do pensamento, dos quais resultam as estruturas de generalização e, consequentemente, a formação de conceitos, quais sejam: no desenvolvimento dos conceitos: pensamento sincrético, pensamento por complexos e pensamento abstrato, rigorosamente conceitual. Na infância precoce, a criança estaria no primeiro período de desenvolvimento do pensamento, o sincretismo, o qual apresenta três fases, descritas a seguir.

Na primeira fase, no que tange ao significado da palavra, o trato com o objeto é realizado por ensaio e erro. A criança faz uso da palavra conforme acha interessante, mas troca quando identifica não corresponder ao que quer significar. A escolha de novos objetos é realizada ao acaso e a percepção tem papel central nesse processo de formação. Na segunda fase, a criança ainda não se orienta pelos vínculos objetivos que descobre nos objetos, mas pelos vínculos subjetivos que a própria percepção lhe sugere; trata-se da fase dos primeiros indícios da organização do campo perceptual. E na terceira fase, a criança atribui único significado aos 
representantes dos diferentes grupos - de objetos, estabelecendo uma coerência bastante incoerente. A criança irá reunir os mais diversos elementos, ainda que sejam desconexos, dado que nos permite depreender que os nexos sejam produzidos por impressões subjetivas.

Nesse sentido, Vigotski (2001, p. 176) ressalta que

\begin{abstract}
O Significado atribuído a alguma palavra pela criança que se encontra nesse desenvolvimento dos conceitos pode, pela aparência, lembrar de fato o significado dado à palavra pelo adulto. Através de palavras dotadas de significado, a criança estabelece a comunicação com os adultos; nessa abundância de laços sincréticos, nesses amontoados sincréticos de objetos desordenados, formados com o auxílio de palavras, estão refletidos, consideravelmente, os laços objetivos, uma vez que coincidem com o vínculo entre as impressões e as percepções da criança.
\end{abstract}

Ora, temos uma criança que inicia o desenvolvimento sobre os significados das palavras e, portanto, a nosso ver, os primeiros passos na construção de conceitos; o desenvolvimento da linguagem interior é condição primária para todo o processo de desenvolvimento da escrita. O próprio Vigotski (2001, p. 316) afirma: "[...] se a linguagem externa aparece na evolução antes da linguagem interna, a escrita, por sua vez, aparece depois da linguagem interior, já pressupondo a sua existência". Dito de outra maneira, a internalização da linguagem possibilita a duplicação do mundo material e a possibilidade de representar e relacionar ideias. A escrita só será possível quando a criança for capaz de tomar um objeto por outro, abstrair e construir o conceito de palavra.

Martins (2013) nos lembra que o êxito na aquisição da escrita não é um dado circunscrito ao momento no qual se 'ensina a criança a escrever', mas depende profundamente da história de seu desenvolvimento. Ao tratar do desenvolvimento do desenho, Vigotski (1995) apontou que as primeiras expressões gráficas da criança transportam indícios gestuais para o papel. Segundo o autor, nesse momento o desenho da criança é um gesto da mão munida com um lápis e exemplifica, dentre outros, com o salto. Aponta que a criança, quando quer desenhar um salto, faz o movimento de saltar com a mão e deixa marcas desse movimento no papel. O autor sinaliza que os primeiros desenhos da criança, suas garatujas, são muito mais gestos que desenhos no verdadeiro sentido da palavra. Entretanto, um caminho importante está sendo trilhado: esta passa a compreender o uso da ferramenta, construindo a ideia de uso do instrumento.

É importante salientar o papel do adulto nessa construção, uma vez que o uso social da palavra é por ele indicado e possibilita à criança perceber que as palavras têm relação com as coisas da realidade. O uso do objeto com significado permite o início da construção das brincadeiras de papéis sociais. Ao discutir essa questão, Vigotski (1996) cita Elkonin e corrobora suas teses, pontuando que, nessa idade, por volta dos três anos, se iniciam as brincadeiras de papéis sociais. A criança já brinca de alimentar sua boneca; entretanto o jogo com significados variados, com a introdução de elementos abstrativos, só ocorre ao final desse período. A criança pequena imita a babá alimentando uma criança, dando de comer a uma boneca. Todavia, sua ação com a boneca não se inscreve em uma atividade na qual a criança se coloca no papel de babá e/ou a boneca no papel de criança. 
O percurso de desenvolvimento da criança culmina em conquistas que lhe permitem tomar uma coisa por outra e representar a realidade externa internamente, pelo uso de signos. Essas conquistas trarão em seu bojo a possibilidade de complexificar a formação de conceitos e, consequentemente, elaborar a ideia de palavra. Essa aquisição ampara-se em operações racionais do pensamento, em especial na generalização e na abstração. E, portanto, temos a possibilidade de desenvolvimento da ideia de palavra, mas para tanto é necessário o desenvolvimento da abstração e da generalização.

\section{Abstração, generalização, imaginação: a construção da palavra como ideia}

As brincadeiras de papéis sociais se configuram como atividade guia para o período entre 4 a 6 anos da criança e podem ser caracterizados pela necessidade desta em fazer o que o adulto faz (PASQUALINE, 2013; LAZARETTI, 2016). Corroborando as autoras, o interesse da criança volta-se para o 'sentido social' das ações com os objetos, como são utilizados pelos adultos no interior das relações sociais, e nesse sentido, afirmam que 'brincar é representar o homem'. Essa conquista possibilita à criança assumir o papel de adulto e de suas funções sociais de trabalho. É possível não apenas reproduzir papéis, fatos, mas generalizar ações com os objetos.

No momento em que se inicia o processo de desenvolvimento das estruturas de generalização, inicia-se também a possibilidade de desenvolvimento de conceito. Ao tratar do conceito de generalização, Vigotski (2001, p. 246, grifo nosso) pondera:

[...] os conceitos psicologicamente concebidos evoluem como significados das palavras. A essência do seu desenvolvimento é, em primeiro lugar, a transição de uma estrutura de generalização a

outra. Em qualquer idade, um conceito expresso por uma palavra representa uma generalização. Mas os significados das palavras evoluem.

No início do processo de generalização, o adulto precisa auxiliar a criança para que ela ultrapasse a materialidade captada sensorialmente. Vigotski (2001) nos apresenta o exemplo do relógio, indicando que a criança precisa conhecer diferentes tipos de relógio para colocá-lo em uma classe de objetos e assim extrair traços, transpô-los a outros, abstrair. Os diferentes tipos de relógios em sua aparência são relógios, porque têm um traço em comum.

A construção dos conceitos, a princípio, está circunscrita ao plano concreto-factual, que corresponde ao que Vigotski (2001) denominou pensamento por complexos. Esse tipo de pensamento abarca cinco fases, a saber: complexo associativo, complexo por coleção, complexo por cadeia, complexo difuso e pseudoconceito. No centro dos complexos radica uma forma e uma estrutura de generalização que a criança estabelece entre objetos e fenômenos da realidade em seu pareamento com as palavras da língua.

De acordo com Vigotski (2001, p. 179), "[...] os signos não aparecem como invenções das crianças, elas os recebem das pessoas que as rodeiam e apenas depois tomam consciência". 
Nessa lógica, os complexos não aparecem de forma particular e espontaneamente nas crianças, mas seguem as tendências objetivas presentes nas produções humanas e transmitidas por meio do ensino. O autor, fundamentado nos estudos de Uznadze, declara que "[...] os verdadeiros conceitos se desenvolvem no pensamento infantil em período relativamente tardio, ao mesmo tempo em que a compreensão mútua entre a criança e o adulto se estabelece muito cedo" (VIGOTSKI, 2001, p. 197). Tal ocorrência revela que essa compreensão é possível, por existir uma coincidência externa entre a estrutura dos complexos e a organização dos conceitos. Vigotski (2001, p. 217) aponta essa questão explanando que adulto e criança "[...] se entendem quando pronunciam a palavra cão, vinculam essa palavra a um mesmo referente, tendo em vista um único concreto, embora, neste caso, um conceba um complexo concreto de cães e o outro um conceito abstrato de cão".

Essa forma de pensar é característica dos períodos pré-escolar e escolar, sendo superada, e essa superação torna-se possível na idade de transição, com o desenvolvimento dos conceitos verdadeiros. Cabe destacar que apenas a organização de atividades de ensino à base de conceitos pode conduzir ao último estágio, qual seja, o pensamento rigorosamente conceitual ou abstrato; se houver atividades organizadas para o ensino de conceitos, o pensamento poderá alcançar o último estágio.

A imaginação infantil, por seu turno, está diretamente relacionada ao desenvolvimento de conceitos e será expressão do sincretismo e do pensamento por complexos. Ao final da infância precoce, a criança percebe a existência dos vínculos objetivos existentes no objeto e "[...] em vez do nexo desconexo que serve de base à imagem sincrética, a criança começa a unificar objetos homogêneos em um grupo comum, a complexificá-los já segundo as leis dos vínculos objetivos que ela descobre em tais objetos" (VIGOTSKI, 2001, p. 179). Realçamos que a imaginação será uma neoformação desse período; é "[...] o novo que está ausente na consciência da criança na primeira infância, absolutamente ausente nos animais, e representa uma forma especificamente humana de atividade da consciência; e, como todas as funções da consciência, forma-se originalmente na ação" (VIGOTSKI, 2008, p. 25). Nessa direção, citamos Elkonin (1998, p.302), quando declara que a fonte fundamental do "[...] enriquecimento do conteúdo dos jogos infantis são as ideias que as crianças têm da realidade circundante; e se não as têm, não se pode levar o jogo a cabo".

Dessa assertiva, destacamos que pensar é relacionar ideias, mas para que haja tal relação é necessário que exista conhecimento acerca da realidade. A riqueza de ideias, bem como as relações internas entre estas, é condição fundante para quaisquer aprendizagens e, consequentemente, da escrita. Nesse sentido, Vigotski (2001 p. 409) expõe que: "Todo pensamento procura unificar alguma coisa, estabelecer uma relação entre as coisas. Todo pensamento tem um movimento, um fluxo, um desdobramento, em suma, o pensamento cumpre alguma função, executa algum trabalho, resolve alguma tarefa".

Ao tratar da questão, Vigotski (2008) indica duas características centrais: afetos (generalizados) e regras. Em sua concepção, a brincadeira de papéis cumpre a função de 
elaboração dos afetos. No entanto, não significa que a mesma surja como resultado de cada desejo não satisfeito isoladamente. Nas palavras do autor, "Isso pressupõe que a criança não tem apenas reações afetivas isoladas em relação a fenômenos isolados, mas tendências afetivas generalizadas externas aos objetos" (VIGOTSKI, 2008, p. 25-26, grifo nosso).

O outro ponto discutido pelo autor refere-se às regras, ressalta que no mundo da brincadeira de papéis há regras rígidas, que refletem as relações sociais entre as pessoas e os objetos. Ao acatar as regras, as crianças renunciam a seus desejos e impulsos imediatos para desempenhar adequadamente o papel que assumiram. Nesse âmbito, o autodomínio da conduta é a principal conquista desse momento do desenvolvimento.

Se na infância temos um nível de consciência incipiente 'não consciência' e a pouca diferenciação entre as formas e o significado das palavras, com o autodomínio da conduta teremos também a possibilidade de uma conscientização mais ampla dos aspectos fônicos e semânticos da palavra. Até a idade escolar, Vigotski (2001, p. 418) alega que a palavra é compreendida pela criança em um movimento único que põe o plano sonoro como parte indivisível do objeto: "Tudo indica tratar-se de um fenômeno inerente a toda a consciência linguística primitiva". A tomada de consciência dos significados das palavras corresponde a uma nova relação que se estabelece entre os aspectos fônico e semântico da linguagem e poderá ser mais bem percebida no período seguinte.

A possibilidade dos jogos simbólicos, nos quais dados objetos passam a ocupar o lugar de outros mediante o trânsito de significados, é para Vigotski um dos mais importantes exercícios objetivamente realizados pela criança pequena por meio dos signos (MARTINS, 2013). Ao tratar das ideias do autor, esta autora destaca que

[...] o objeto cumpre, no jogo simbólico, uma função substitutiva, e os gestos a ele relacionados conferem o significado situacional que assumem.[...]a criança extrai do objeto traços que assumem função simbólica, reconfigurando totalmente seu significado. Portanto, a escolha do objeto substitutivo, lúdico, não é um ato aleatório, mas resultado de uma análise realizada pela criança. (MARTINS, 2013, p.186).

E prossegue, trazendo as relações entre o simbólico e o desenvolvimento da linguagem oral e a linguagem escrita:

Vigotski irá atestar para uma estreita unidade entre as representações simbólicas no jogo e o
desenvolvimento da abstração requerida tanto à linguagem oral quanto à linguagem escrita.
Em sintonia com os jogos simbólicos desponta o desenho, no qual ocorre, de modo gradativa,
a passagem da garatuja à representação de objetos e fenômenos por meio da representação de
elementos gráficos. [...] A evolução do desenho acompanha, por sua vez, os próprios domínios
da linguagem oral, havendo uma estreita relação entre eles. (MARTINS, 2013, p.186, grifo nosso).

Em relação à possibilidade de o desenho começar a designar por si mesmo o objeto, Vigotski (1995, p.190) discorre acerca da conclusão do experimento de Ch. Buhler, em que o pesquisador: 
[...] observou que os traços do desenho infantil progridem gradualmente: a designação verbal deixa de ser posterior para ser simultânea. Acaba finalmente se tornando o nome que é anterior ao desenho. Isso significa que a partir da designação posterior da forma desenhada se desenvolve a intenção de representar algo indeterminado. A linguagem que se antecipa contribui para um importante progresso mental.

A linguagem que se antecipa ao desenho corrobora para um importante desenvolvimento mental - a intenção de desenhar algo. Essa possibilidade de planejar o que será desenhado terá importância central para o desenvolvimento da escrita, entretanto o desenho infantil corresponde a uma fase anterior à escrita e ainda por sua função psicológica o desenho infantil é um tipo peculiar de linguagem gráfica, um relato gráfico sobre algo, "[...] o desenho da criança é muito mais uma linguagem que uma representação" (VIGOTSKI, 1995, p. 199). Martins (2013, p. 187), ao sintetizar as ideias de Vigotski e Luria, sublinha as diferenças entre desenho e escrita:

Da mesma forma que a palavra o desenho, adquire apenas uma função simbólica de primeiro grau, ou seja, ocupa o lugar do objeto, representa-o.[...] ou seja, a criança desenha coisas e não palavras. Diferentemente, à escrita corresponde uma função simbólica de segundo grau, uma vez que não se estrutura em uma relação direta com o objeto, mas com a palavra que o designa.

A autora complementa que a linguagem oral está para o objeto tanto quanto a escrita está para a linguagem oral, de sorte que a representação gráfica se revela condicionada pela capacidade abstrativa advinda do desenvolvimento do pensamento. Tal assertiva não significa que haja uma ruptura entre a palavra escrita e o objeto que representa; outrossim, aponta uma relação de segunda ordem entre ambos. É preciso lembrar que na Educação Infantil a fala interna está em desenvolvimento, e somente a partir de sua construção será possível o desenvolvimento da escrita. As investigações realizadas por Vigotski (2001, p. 312) nos ajudam a compreender a evolução da escrita:

Como mostra a nossa investigação, a linguagem escrita requer para o seu transcurso pelo menos um desenvolvimento mínimo de um alto grau de abstração. Trata-se de uma linguagem sem seu aspecto musical, entonacional, expressivo, em suma, sonoro. É uma linguagem de pensamento, de representação, mas uma linguagem desprovida do traço mais substancial da fala - o som material.

Queremos salientar que a possibilidade de abstração, no nível abordado na citação, apenas será possível se a criança possuir um conjunto de condições psicológicas já trilhado, se ela for capaz de abstrair, por meio da linguagem de sons, o mundo material. Para tanto, o trabalho do professor precisa centrar-se no processo de representação e possibilidades de desenvolvimento de conceitos, buscando gerar na criança, ao final desse processo, a necessidade de representar graficamente a sua ideia. Só assim o processo de alfabetização terá sucesso, lembrando que grafar ideias implica ser capaz de abstrair o aspecto sensorial da fala e avançar na construção de uma "[...] linguagem abstrata, que não usa palavras mas representações de palavras" (VIGOTSKI, 2001, p. 313). Para escrever, a criança precisa ter consciência da estrutura sonora da palavra, desmembrá-la e restaurá-la voluntariamente nos sinais escritos graças aos vínculos internos entre linguagem oral e linguagem escrita. Nessa direção, é possível afirmar que o domínio da segunda linguagem escrita requalifica a primeira: a linguagem oral. Outro destaque importante diz respeito aos motivos envolvidos na tarefa 
de escrever algo. Enquanto as situações que envolvem a linguagem oral criam a todo tempo a motivação de nova flexão da fala, a linguagem escrita é mais arbitrária, e demanda a criação de situações objetivas e subjetivas - da alçada do pensamento - para sua realização. Sendo assim, a escrita demanda voluntariedade, não se apartando da esfera dos motivos. Compreender os motivos que levam a criança à ação de representar suas ideias graficamente é central para o início do processo de alfabetização. De acordo com Vigotski (2001), os motivos que orientam a criança em direção à escrita Ihes são pouco acessíveis no início do processo, e por vezes a criança tem uma noção muito vaga da utilidade desse expediente. Isso se soma ao fato de que, para se apropriar dessa linguagem, é necessário agir de forma voluntária, intencional e, por conseguinte, caberá aos adultos, especialmente aos professores, gerar a necessidade inicial na criança para tal feito.

\section{Considerações Finais}

Pelo exposto visamos demonstrar que o conceito de palavra, elaborado gradativamente ao longo do desenvolvimento cultural da criança, se revela unidade de análise não apenas das articulações entre linguagem e pensamento, mas, sobretudo, para a exegese das vinculações internas essenciais que se estabelecem entre linguagem oral e linguagem escrita. A nosso juízo, com fundamento na psicologia histórico-cultural, o ato psíquico consubstanciado na escrita não radica no trato ou no uso externo que a criança faz da palavra oralmente, mas sim de sua representação como conceito. Advogamos, pois, que a formação do conceito de palavra, tanto em sua dimensão semântica quanto em sua morfologia e fonética, se impõe como tarefa de um ensino desenvolvente desde a educação infantil, construindo-se, assim, o substrato para a aquisição da escrita propriamente dita nos anos de escolarização subsequentes.

A exposição em tela não esgota, em toda a sua complexidade, a análise das particularidades implicadas na estrutura e na dinâmica da aquisição da escrita; não obstante, permite-nos pontuar questões que julgamos relevantes para a orientação do ensino escolar voltado à escritura. A primeira diz respeito ao fato de que a escrita é um processo altamente complexo que demanda da criança o autocontrole do próprio comportamento. Esse autocontrole resulta da complexificação das funções psíquicas, subjugando-se à internalização de signos que, por seu turno, identifica-se com o universo simbólico disponibilizado à apropriação pela criança. Como esse processo não se institui natural e espontaneamente, ofertar condições para que ocorra deve se impor como objetivo nuclear da educação escolar das crianças pequenas. A segunda questão se refere ao fato de que, na escrita, a criança precisa ter consciência da estrutura sonora da palavra, desmembrá-la e restaurá-la voluntariamente nos sinais escritos. Se na apropriação da linguagem oral o grande desfio da criança é compreender que cada palavra designa um objeto, na escrita ela precisa compreender que para cada palavra existe uma representação gráfica. 
ELKONIN, D. B. O desenvolvimento do jogo na idade pré-escolar. In: ELKONIN, D. B. Psicologia do jogo. Trad. Álvaro Cabral. São Paulo: Martins Fontes, 1998. p. 233-396.

LAZARETTI, L. Idade pré-escolar (3-6 anos) e a educação infantil: a brincadeira de papéis sociais e o ensino sistematizado. In: MARTINS, L. M.; ABRANTES, A. A.; FACCl, M. G. D. (Org.). Periodização histórico-cultural do desenvolvimento psíquico: do nascimento à velhice. Campinas: Autores Associados, 2016. p. 129-148. (Coleção educação contemporânea).

LEONTIEV, A. N. Desenvolvimento do psiquismo. Lisboa: Livros Horizonte, 1978.

MARTINS, L.M. O Desenvolvimento do psiquismo e a educação escolar: contribuições à luz da psicologia histórico-cultural e da pedagogia histórico-crítica. Campinas: Autores Associados, 2013.

MENDONÇA, F. W. A organização da atividade de ensino como processo formativo do professor alfabetizador: contribuições da teoria histórico-cultural. 2017. 247 f. Tese (Doutorado em Educação) - Universidade Estadual de Maringá, Maringá, 2017.

PASQUALINI, J. C. Periodização do desenvolvimento psíquico à luz da Escola de Vigotski: a teoria histórico-cultural do desenvolvimento infantil e suas implicações pedagógicas. In: MARSIGLIA, A. C. G. (Org.). Infância e pedagogia histórico-crítica. Campinas: Autores Associados, 2013.

PORTO, K. M.; MARTINS, L. M. Formação de sistemas conceituais e o desenvolvimento do pensamento: implicações para a educação escolar. Nuances: Estudos sobre Educação, Presidente Prudente, v. 29, n. 3, p. 4-22, 2018.

VIGOTSKI, L. S. A brincadeira e o seu papel no desenvolvimento psíquico da criança. Trad. Zoia Prestes. Revista Virtual de Gestão de Iniciativas Sociais, Rio de Janeiro, n. 8, p. 23-36, 2007.

VIGOTSKI, L. S. O método instrumental em psicologia. In: TEORIA e método em psicologia. São Paulo: Martins Fontes, 2004. p. 93-101.

VIGOTSKI, L. S. Obras escogidas. Madrid: Visor, 1995. Tomo III.

VIGOTSKI, L. S. Obras escogidas. Madrid: Visor, 1996. Tomo IV.

VIGOTSKI, L. S. As raízes genéticas do pensamento e da linguagem. In: VIGOTSKI, L. S. A construção do pensamento e da linguagem. São Paulo: Martins Fontes, 2001. p.109-150.

VIGOTSKI, L. S.; LURIA, A. R. El instrumento y el signo em El desarrollo Del niño. Madrid: Fundación Infancia y Aprendizage, 2007. 